\title{
The Effects of Multisensory Method and Cognitive Skills Training on Perceptual Performance and Reading Ability among Dyslexic Students in Tehran-Iran
}

\author{
Seyedmorteza Nourbakhsh ${ }^{1}$, Mariani Mansor ${ }^{1}$, Maznah Baba ${ }^{2}$ \& Zainal Madon ${ }^{1}$ \\ ${ }^{1}$ Faculty of Human Ecology, Universiti Putra Malaysia, Serdang, Malaysia \\ ${ }^{2}$ Faculty of Educational Studies, Universiti Putra Malaysia, Serdang, Malaysia \\ Correspondence: Seyed Morteza Nourbakhsh, Faculty of Human Ecology, Universiti Putra Malaysia, Serdang, \\ 43400, Malaysia. Tel: 98-912-205-2582. E-mail: nourbakhsh.s.m@gmail.com
}

Received: February 12, $2013 \quad$ Accepted: April 22, $2013 \quad$ Online Published: May 21, 2013

doi:10.5539/ijps.v5n2p92

URL: http://dx.doi.org/10.5539/ijps.v5n2p92

\begin{abstract}
The purpose of this research is to examine the effects of cognitive (cognitive skills training) and developmental intervention (sensory-perceptual skills training) on performance and reading ability of dyslexic students. In the study 60 dyslexic students participated and they were divided into three experimental groups including 20 students as the first experimental group (E1), 20 students as the second experimental group (E2), and 20 students as the control group (C). The effectiveness of the 16-session intervention for both E1 and E2 groups was measured by Reading and Dyslexic test (RTD) as screening test at the beginning and followed by the Bender Visual Motor Gestalt Test (BVMGT) and Rey-Osterrieth Complex Figure test (ROCF). The results were analyzed by using analysis of variance (ANOVA) to compare mean scores among the three dyslexic groups after intervention. Findings suggest that developmental intervention significantly improves RDT, BVMGT and memory scale of ROCF performance of dyslexic students. However, cognitive intervention does not appear to significantly increase performance of the students compared to the control group.
\end{abstract}

Keywords: cognitive skills training, cognitive intervention, sensory-perceptual skills training, developmental intervention, dyslexia

\section{Introduction}

Dyslexia is a specific learning disability of difficulty with accurate and/or fluent word recognition by poor spelling and decoding ability. Most dyslexic students do not enjoy academic achievement and educational inadequacy leads to poor negative consequences, low self-concept, emotional disorder such as isolation, depression, loneliness, even suicide (Mercer \& Pullen, 2005), motivational and social cognition problems, and also behavioral disorders (McNamara, 2007). To determine accurate methods for solving learning difficulties, several theories have been advanced. Amongst many theories, cognitive and developmental approaches are used to answer problems related to learning disabilities. According to the cognitive approach the existence of one or more basic cognitive processing and meta-cognitive deficits causes LD, so that they cannot easily learn how to learn, how to control, and how to direct their thoughts in order to learn (Lerner \& Kline, 2006). According to Piaget (1959), the child needs to have time, to perform motor activities. Thus, the development of motor-perceptual activities depends on age and dyslexic students need more time to develop these abilities. On the other hand, Vygotsky's theory suggests that what children can do today with assistance, they will be able to do tomorrow proficiently on their own. According to this theory, with the appropriate guidance, performance can precede competence (Cazdan, 1981). As research has indicated, children with dyslexia have different problems in different stages of information processing such as difficulties with tasks involving processing of visual-spatial information (Weiler, Bernstein, Bellinger, \& Waber, 2002; Menghini et al., 2011), more cognitive inhibition (Wang, Tasi, \& Yang, 2012), difficulties in higher-order processing or executive control processes (Braiard, 2005; Mercer \& Pullen, 2009), deficits in visual attention span (Talcott et al., 2000; Bosse, Tainturier, \& Valdois, 2007), difficulties in perceptual processing speed (Tallal, Miller, \& Fitch, 1995; Stenneken et al., 2011) and memory deficits (Thomson, 1984). According to this, a considerable amount of literature has been published on remediating cognitive and metacognitive deficits in different stages of information processing in children with 
dyslexia. These studies focus on improving attention span and memories strategies in children with dyslexia, practicing to retain abstract information (Vaughn el at., 2003; Vaughn \& Roberts, 2007); increasing phonological awareness and skills (Schneider et al., 2000; Vadasy et al., 2002); and training decoding, and word reading, writing exercises, and also practicing comprehension strategies while reading texts (Scammacca et al., 2007).

However, developmental theory assumes immaturity is a serious cause of LD. One of the earliest single-factor theories which was developed by Orton (1937) attributed reading disability to an incomplete cerebral dominance. Orton suggested that the disorder is caused by a neurological-maturational lag resulting in delayed lateral dominance for language which leads to disruptions in perceptual functioning (Olitsky \& Nelson, 2006). Orton-Gillingham methodology uses visual, auditory, and kinesthetic associations to help students learn sound-symbol relationships. A large and growing body of literature has indicated the effectiveness of employing a multisensory remedial training program with LDs children (Donah, 2012; Falzona, Callejab, \& Muscatc, 2011; Hazoury, Oweini, \& Bahous, 2009; Joshi, Dahlgren, \& Boulware, 2002; Oakland, Black, Stanford, Nussbaum, \& Balise, 1998; B. Shaywitz et al., 2004; Torgesen et al., 1999; Thorton, Jones, and Toohey, 1982; Foorman et al., 1997; Mihandoost and Elias, 2001; Dev, Doyle, Valente, 2002).

A study conducted by Thorton, Jones, and Toohey (1982) implemented a multi-sensory teaching program incorporating visual learning with oral prompts and finger-tracing, for students' grades two through six. Findings indicated all of the grade levels - except grade two - showed marked improvement from the pretest to posttest. Another study by Foorman et al. (1997) compared three types of reading interventions for students with reading problems in $2^{\text {nd }}$ and $3^{\text {rd }}$ grades in 13 different schools. A synthetic phonics program based on the Orton-Gillingham method was compared with an analytic phonics program and a sight-word program It was found that the two phonics groups out-performed the sight-word group on phonological analysis (effect sizes $0.23-0.59$ ) but not on word reading, and the synthetic phonics group out-performed the analytic phonics group on both phonological analysis (ES 0.39) and word reading (ES 0.38).

Mihandoost and Elias (2001) in a research investigated the differences in reading attitude and reading comprehension among dyslexic students following the Barton intervention program. Results of the study showed a significant difference between the control group and the experimental group following the Barton intervention program. They concluded that multi-sensory methods such as the Barton intervention program, can improve the dyslexic children's reading comprehension. Dev, Doyle, and Valente (2002) used the Orton-Gillingham technique, which involves visual, auditory, and kinesthetic modalities, with first grade children at the special education level. These children improved enough in their reading abilities to advance them out of the special education level.

There are not many available studies on dyslexia in Iran compared to other countries (Fallahchai 1995; Seif-e-Naraghy \& Nadery 2005; Ghonsooly, 2009; Narimani et al., 2009; Sedaghati et al., 2010). The problem in this research is related to the challenges in providing efficient interventions to modify the perceptual abilities of children with dyslexia. Therefore, the study aims to compare the effectiveness of multisensory method adopted from the Orton-Gillingham program based on maturational lag theory (developmental approach) and cognitive and metacognitive skills training based on information processing theory (cognitive approach) on reading and perceptual abilities of students with dyslexia. The study hypothesizes that the scores in Reading and Dyslexic test (RTD), Bender Visual Motor Gestalt Test (BVMGT) and Rey-Osterrieth Complex Figure test (ROCF) are different for developmental intervention, cognitive intervention, and control groups after intervention. It is expected to observe different test scores among the groups after intervention as each intervention is based on a different underlying theory and the study aims to compare the effectiveness of the developmental and cognitive theories.

\section{Method}

Primary $3^{\text {rd }}$ grade students with dyslexia who were referred to two Specific Learning Disability Centers in Tehran (Iran) participated in the study. Participants were selected from referrals by ordinary school to public Specific Learning Disability Centers in Tehran, Iran. Criteria for participation in the study were that the dyslexic children: (1) did not have a prior history of treatment for dyslexia, (2) had a confirmed clinical diagnosis of dyslexia using Diagnostic and Statistical Manual of Mental Disorders, Fourth Edition (DSM-IV) criteria by experienced psychologists in the field of exceptional children who were working in the centers, including (a) difficulty with accurate or fluent word recognition, or both, (b) deficit in word decoding, (c) problem in reading rate, (d) weakness in prosody (oral reading with expression), and (e) reading comprehension (Reading disorder, DSM-IV codes: F81.0/315.00), and finally, (3) met T score of 70 or above on average for five subscales in scale of RDT (Iranian version). From these students, 60 participants were matched by statistical indicators in RDT and 
they were divided into three groups (two experimental groups and one control group) using random assignment.

The study compares the effectiveness of multisensory method and cognitive skills training on reading and perceptual abilities of students with dyslexia. Multisensory method focused on three sensory modalities simultaneously (visual, auditory, and tactile) provided in seven lessons in 16 sessions/week. The seven lessons include visual perception skills, auditory perception skills, visual tracking skills, alphabet tracking skills in reading, alphabet track, spell tracking skills in reading, and word tracking skills in reading. Developmental intervention was administered on the E1 group and cognitive intervention was administered on the E2 group, while no related intervention was received by the control group. On the other hand, Cognitive strategies, administered on the E2 group, comprised multiple and flexible strategies, self-monitoring, and meta-cognition to help the participants enhance their perceptual performance and reading skills. The cognitive interventional program was adopted from Swanson (1993), Lerner and Kline (2006), and Christo et al. (2009). The intervention used in this study provided five lessons in 16 sessions/week. The lessons included Memory strategies, Word recognition skills, Reading accuracy and fluency, Self-questioning strategy followed by visual imagery, and Meta-cognition strategies.

This research examined three respective tests including Reading and Dyslexic test (RTD), Bender Visual Motor Gestalt Test (BVMGT), and Rey-Osterrieth Complex Figure (ROCF) test. Reading and Dyslexia Test (RDT) was standardized in Iran and is an individually administered test for diagnosing reading ability in dyslexic students. The test contains five subtests which evaluate reading abilities including Word Reading, Word Chains Reading, Word Comprehension, Phoneme Deletion, and Pseudo-Word Reading. Each response in these subtests is considered as one score and total scores are computed using standard score. The BVMGT as a maturational test which implies a close relationship between the ability to perceive process and reproduce designs was used as a perceptual tool of the study. In this test the examinee had to reproduce on a blank piece of paper one figure at a time. The test provides developmental data on child perceptual maturity and has been recognized as one of the most useful tools in the assessment of neurological functioning (Lerner \& Kline, 2006). Scoring is based on drawn difficulties. These difficulties may indicate poor visual-motor abilities that include: angular difficulty, bizarre doodling, closure difficulty, cohesion, collision and so on (Groth-Marnat, 2003). Taylor and Sennott (1984) found that the test as a visual perceptual test is a standard instrument for diagnosis and prescription among LDs, and even the test has long been used in the diagnosis of LDs within the school boards. The Bender-Gestalt test with young children reveals inter-scorer reliability to be very high with correlations of .90 and above. Rey-Osterrieth Complex Figure test (ROCF) permits assessment of a variety of cognitive processes, including planning and organizational skills and problem-solving strategies, as well as perceptual, motor, and memory functions. The test is a neuropsychological assessment in which examinees are asked to reproduce a complicated line drawing, first by copying and then from memory. In the Copy condition, the examinee is given a piece of paper and a pencil, and the stimulus figure is placed in front of the examinee. In the immediate recall condition, after a short delay, the examinee is asked to reproduce the figure from memory. Andre Rey defined 18 units of the drawing and assigned point values of 0 to 2 to each unit depending on the degree to which the units are correctly drawn and placed. Findings of Mirhashemi and Ahadi (2006) show that the test has significant validity (Copying scale, $0.77 ; \mathrm{P}<0.01$ and memory scale, $0.51, \mathrm{P}<0.05)$ and reliability $(0.624, \mathrm{P}<0.01)$ for memory scale in the Iranian population.

\section{Results}

In experimental research it is assumed that there is no significant difference between experimental group and control group at pre intervention. Here, prior to testing the research hypotheses, this assumption is investigated using a series of one-way ANOVA. The results are presented in order as follows: A one-way ANOVA was used to test RDT difference among three groups. As expected, the result of pre-intervention among three dyslexic groups did not differ significantly, [F $(2.57)=.178, P=.837]$. The result revealed that null hypothesis related to means differences in RDT among dyslexics at pre-intervention was accepted. Also a one-way ANOVA was used to test BVMGT difference among three groups. As expected, the result of pre-test among three groups did not differ significantly, $[\mathrm{F}(2.57)=.662, P=.520]$. The result showed null hypothesis related to means differences in BVMGT at pre intervention was accepted. Likewise a one-way ANOVA was used to test ROCFT (copy scale) difference among three groups. As expected, the result of pre-intervention among three groups did not differ significantly, $[\mathrm{F}(2.57)=.605, P=.550]$. The result showed null hypothesis of mean differences in three dyslexic groups in copy scale of ROCFT was accepted. Moreover a one-way ANOVA was used to test ROCFT (memory scale) difference among three groups. As expected, the result of pre-intervention among three groups did not differ significantly, $[\mathrm{F}(2.57)=2,328, P=.107]$. As expected the result showed that null hypothesis of memory scale of ROCFT among dyslexic groups at pre-intervention was accepted. 
Table 1. Test scores differences in experimental groups and control group at pre intervention

\begin{tabular}{|c|c|c|c|c|c|c|}
\hline subscale & Group & $\mathrm{N}$ & Mean & $\mathrm{SD}$ & $\mathrm{F}$ & $\mathrm{P}$ \\
\hline \multirow[t]{3}{*}{ RDT } & $\mathrm{C}$ & 20 & 63.84 & 10.75 & \multirow{3}{*}{.178} & \multirow{3}{*}{$.837^{\text {n.s }}$} \\
\hline & E1 & 20 & 62.31 & 11.63 & & \\
\hline & E2 & 20 & 64.54 & 13.63 & & \\
\hline \multirow[t]{3}{*}{ BVMGT } & $\mathrm{C}$ & 20 & 1.74 & 1.05 & \multirow{3}{*}{.662} & \multirow{3}{*}{$.520^{\text {n.s }}$} \\
\hline & E1 & 20 & 1.43 & 1.35 & & \\
\hline & E2 & 20 & 1.85 & 1.18 & & \\
\hline \multirow{3}{*}{$\begin{array}{l}\text { ROCFT copy } \\
\text { scale }\end{array}$} & $\mathrm{C}$ & 20 & -2.95 & 2.22 & \multirow{3}{*}{.605} & \multirow{3}{*}{$.550^{\text {n.s }}$} \\
\hline & E1 & 20 & -3.72 & 2.76 & & \\
\hline & E2 & 20 & -3.80 & 3.09 & & \\
\hline ROCFT & $\mathrm{C}$ & 20 & -8.25 & 1.00 & \multirow{3}{*}{2.33} & \multirow{3}{*}{$.107^{\mathrm{n} . \mathrm{s}}$} \\
\hline \multirow[t]{2}{*}{ Memory scale } & E1 & 20 & -6.74 & 2.64 & & \\
\hline & E2 & 20 & -7.93 & 2.88 & & \\
\hline
\end{tabular}

n.s: Not significant

A one-way between group ANOVA was performed to compare the effect of interventions on RDT score of E1, E2 and control groups. As presented in Table 1, the result revealed that the RDT scores of the three dyslexic groups after intervention was significantly different $[\mathrm{F}(2,57)=8.55, \mathrm{P}<.05)]$. The post hoc comparison using the tukey test indicated that the mean score of RDT for E1 group (Mean=83.38, SD=9.15) was significantly different from control group (Mean=65.98, $\mathrm{SD}=13,63$ ). However, E2 group (Mean = 75.09, $\mathrm{SD}=16.19$ ) did not differ significantly from that of the control group.

Table 2. Test scores differences in experimental groups and control group after intervention

\begin{tabular}{llllllll}
\hline \multirow{2}{*}{ Variable } & \multicolumn{7}{c}{ Groups } \\
\cline { 2 - 7 } & \multicolumn{2}{l}{ Control group $(\mathrm{n}=20)$} & \multicolumn{2}{c}{ E1 group $(\mathrm{n}=20)$} & \multicolumn{2}{l}{ E2 group $(\mathrm{n}=20)$} & \multirow{2}{*}{ P value } \\
& Mean & $\mathrm{SD}$ & Mean & $\mathrm{SD}$ & Mean & $\mathrm{SD}$ & \\
\hline RDT & 65.98 & 13.63 & 83.38 & 9.15 & 75.09 & 16.19 & $.001^{*}$ \\
BVMGT & 1.36 & .75 & .6 & 1.16 & .89 & .82 & $.040^{*}$ \\
ROCF (copy scale) & -2.32 & 1.93 & -2.47 & 2.9 & -1.77 & 2.5 & .639 \\
ROCF (memory scale) & -7.9 & 1.12 & -5.31 & 2.47 & -6.55 & 1.74 & $.00^{*}$ \\
\hline
\end{tabular}

*: Significant

The second ANOVA was conducted to investigate BVMGT score difference among the three dyslexic groups. There was a significant difference between BVMGT score of control group, the group receiving developmental intervention (E1), and the group under cognitive intervention (E2) at the $\mathrm{p}<.05$ level $[\mathrm{F}(2,57)=0.04, \mathrm{p}<.05]$. Post hoc comparisons using the Tukey HSD test indicated that the mean score for E1 group (Mean=.6, $\mathrm{SD}=1.16$ ) was significantly less than that of control group (Mean=1.36, $\mathrm{SD}=.75$ ). In contrast, there was no significant difference between $\mathrm{E} 2$ group's mean scores (Mean=.89, $\mathrm{SD}=.82$ ) compared to those of the control group. Therefore, developmental interventions decreased the mean score error in the dyslexic group under the intervention compared to the control group.

As indicated in Table 1, there was no significant difference among the three groups in ROCF (copy scale) test [F $(2.57)=.451, \mathrm{P}=.639]$. However, a significant difference was observed in ROCF (memory scale) among the three dyslexic groups $[\mathrm{F}(2,57)=9.73, \mathrm{p}<.05]$. The post hoc comparison using the tukey HSD test indicated that the mean scores for $\mathrm{E} 1$ group (Mean $=-5.31, \mathrm{SD}=2.47$ ) were significantly different from that of the control 
group $($ Mean $=-7.9, \mathrm{SD}=1.12)$; However, E2 group (Mean $=-6.55, \mathrm{SD}=1.74)$ was not significantly different from control group.

\section{Discussion}

The critical issue in explanation, prediction, and management of perceptual abilities in students with dyslexia is whether perceptual disabilities lead to dyslexia as supposed by cognitive impairment or developmental lag and immaturity lead to dyslexia. This study examined the effectiveness of two types of intervention (developmental and cognitive) on the perception and sequential reading ability of dyslexic students. Results showed that the mean score in the group following the developmental intervention (E1 group) was significantly different from the control group in RDT, BVMG test, memory scale of ROCF test. However, no significant difference was observed in copy scale of ROCF test. Besides, findings highlighted that the mean score in the group following cognitive intervention (E2 group) was not significantly different from the control group in most of the variables. Therefore, the effect of multisensory method on performance of learning-based tests was more than cognitive skills training. An explanation for more effectiveness of multisensory method is that the multisensory training builds many visual-auditory associations in learning grapheme-phoneme correspondences through kinesthetic activities, develops attention span to details within letters or words that help in word retrieval from long-term memory, reduces boredom, increases the student's involvement time in learning and finally, it provides more feedback to the instructors (Hazoury et al., 2009; Uhry \& Clark, 2005). Consistent with the findings of this research, O'Brien, Cermak, and Murray (1988) showed that interventions can improve visual conditions and for this reason motor performance would be improved. Murray, Cermak, and O'Brien (1990) emphasized that visual-perceptual deficits are the main characteristic of children with developmental dyspraxia. For this reason many occupational therapists treating dyslexic students focus on the visual-perceptual problem, visual-motor difficulties, and motor incoordination. Geschwind and Galaburda (1985) pointed out that dyslexic children have average visual-perceptual skills (cited by O'Brien, et al., 1988).

As students who received developmental intervention performed better than control group, it is also concluded that developmental delay is more likely to be the reason for dyslexia. It should be noted that developmental intervention emphasized developmental delays in several areas of maturation which is the major cause of dyslexia (Lerner \& Kline, 2006). Dyslexia happens when students are pressed into performing school tasks before they are capable of doing so. Then the demand of schooling can cause failure by requiring students to carry out something beyond their ability, or readiness, at a given stage of maturation (Bender, 1957, cited by Lerner \& Kline, 2006). The development of visual-motor activities depends on perceptual-motor functioning and in line with the developmental approach, dyslexic students need more time to develop these skills. Non-dyslexic people learn in a multisensory way automatically while dyslexic learners have to be trained to see and hear words as they learn. (NIACE, 2004). This study helped to determine the most effective method of intervention for children with dyslexia, and it ultimately helps to implement new special education for all school systems.

The findings of this research basically reflect what Piaget (1959) calls the concrete operational stages; therefore nine year old dyslexic students are still in concrete operational stages. The results of this research parallel those of Murray et al. (1990) which mentioned that the main characteristic of developmental dyslexia is visual-perceptual functioning deficits. Further investigation goals comprising duration of more than six months, follow up tests to study effectiveness of the intervention across time and replication of the research in other populations are recommended.

\section{References}

American Psychological Association. (1972). Ethical standards of psychologists. Washington, DC: American Psychological Association.

Anderson, C. A., Gentile, D. A., \& Buckley, K. E. (2007). Violent video game effects on children and adolescents: Theory, research and public policy. http://dx.doi.org/10.1093/acprof:oso/9780195309836.001.0001

Beck, C. A. J., \& Sales, B. D. (2001). Family mediation: Facts, myths, and future prospects. Washington, DC: American Psychological Association. http://dx.doi.org/10.1037/10401-000

Bender, L. A., \& Doell, B. (1957). Biological evaluation of proteins: A new aspect. British Journal of Nutrition, 11(02), 140-148. http://dx.doi.org/10.1079/BJN19570029

Bosse, M. L., Tainturier, M. J., \& Valdois, S. (2007). Developmental dyslexia: The visual attention span deficit hypothesis. Cognition, 104(2), 198-230. http://dx.doi.org/10.1016/j.cognition.2006.05.009

Braiard, R. B. (2005). A Comparison Disabled Children and Non-Learning Disability Children on the Rorschach: 
An Information Processing perceptive.

Cazden, C. (1981). Performance before competence: Assistance to child discourse in the zone of proximal development. Quarterly Newsletter of the Laboratory of Comparative Human Cognition, 3(1), 5-8.

Christo, C., Davis, J., \& Brock, S. (2009). Identifying, Assessing, and Treating Dyslexia at School. New York: Springer Verlag.

Dev, P. C., Doyle, B. A., \& Valente, B. (2002). Labels needn't stick: “At-risk" first graders rescued with appropriate intervention. Journal of Education for Students Placed at Risk, 7(3), 327-332. http://dx.doi.org/10.1207/S15327671ESPR0703_3

Donah, S. (2012). Site Director, International Multisensory Structured. Retrieved from http://www.zoominfo.com/\#!search/profile/person

Fallahchai, H. (1995). An examination of reading and writing disorders among primary school students. AM, University of Tarbiyat-Modarres, Unpublished MA thesis.

Falzona, R., Callejab, C., \& Muscatc, C. (2011). Structured Multisensory Techniques in Reading and Learning Patterns.

Foorman, B. R., Francis, D. J., Winikates, D., Mehta, P., Schatschneider, C., \& Fletcher, J. M. (1997). Early interventions for children with reading disabilities. Scientific Studies of Reading, 1, 255-276. http://dx.doi.org/10.1207/s1532799xssr0103_5

Geschwind, N., \& Galaburda, A. M. (1985). Cerebral lateralization. Archives ofNeurology, 42, 428-459. http://dx.doi.org/10.1001/archneur.1985.04060050026008

Ghonsooly, B. (2009). Dyslexia in Persian Language. Journal of Language and Literature of Faculty of Letters and Humanities, 41(3), 247-264.

Hazoury, K. H., Oweini, A. A., \& Bahous, R. (2009). A multisensory approach to teach arabic decoding to students with dyslexia. Learning Disabilities A Contemporary Journal, 1, 1-20.

Joshi, R. M., Dahlgren, M., \& Boulware, G. R. (2002). Teaching reading in an inner city school through a

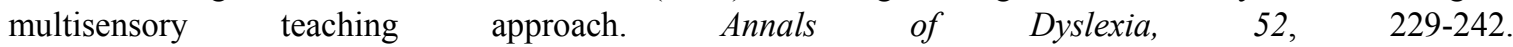
http://dx.doi.org/10.1007/s11881-002-0014-9

Lerner, J., \& Kline, W. (2006). Learning Disability Characteristic \& teaching strategies (10th ed.). Boston Houghton Mifflin Company.

McNamara, B. E. (2007). Learning Disabilities. Bridging the gap between research and classroom practices. New Jersey printice Hall.

Menghini, D., Finzi, A., Carlesimo, A. G., \& Vicari, S. (2011). Working Memory Impairment in Children with Developmental Dyslexia: Is it Just a Phonological Deficit? Journal Developmental Neuropsychology, 36(2), 199-213. http://dx.doi.org/10.1080/87565641.2010.549868

Mercer, C. D., \& Pullen, P. C. (2005). Students with learning Disabilities (6th ed.). New Jersey: Prentice Hall.

Mercer, C. D., \& Pullen, P. C. (2009). Student with learning Disabilities (7th ed.). New Jersey: Prentice Hall.

Mihandoost, Z., \& Elias, H. (2001). The effectiveness of Barton's intervention program on reading comprehention and reading attitude of students with dyslexia i. Iran J Psychiatry Behav Sc, 5(2), 43-52.

Mirhashemi, M., \& Ahadi, H. (2006). Normalization of complex figure test.

Murray, E. A., Cermak, S. A., \& O’Brien, V. (1990). The relationship between form and space perception, constructional abilities, and clumsiness in children. The American Journal of Occupational Therapy, 44(7), 623-628. http://dx.doi.org/10.5014/ajot.44.7.623

Narimani, M., Sadeghi, A., Homeily, N., \& Siahpoosh, H. (2009). A Comparison of Emotional Intelligence and Behavior Problems in Dyslexic and Non-Dyslexic Boys. Journal of Applied Science, 9(7), 1388-1390. http://dx.doi.org/10.3923/jas.2009.1388.1392

NIACE, L. (2004). The National Institute of Adult Continuing Education.

Oakland, T., Black, J. L., Stanford, G. N. L. N., \& R., B. R. (1998). An evaluation of the dyslexia training program: A multisensory method for promoting reading in students with reading disabilities. Journal of Learning Disabilities, 31(2), 140-147. http://dx.doi.org/10.1177/002221949803100204

O'Brien, V., Cermak, S. A., \& Murray, E. A. (1988). Visual perceptual motor abilities and clllffisiness in children 
with and without learning disabilities. The American Journal of Occupational Therapy. http://dx.doi.org/10.5014/ajot.42.6.359

Olitsky, S., \& Nelson, L. B. (2006). The Eye and Reading Disorders (Vol. 5). Lippincott Williams \& Wilkins.

Orton, S. (1937). Reading, writing and speech problems in children.

Piaget, J., \& Inhelder, B. (1959). La genèse des structures logiquesélémentaires.

Scammacca, N., Vaughn, S., Roberts, G., Wanzek, J., \& Torgesen, J. K. (2007). Extensive reading interventions in Grade K-3: From research to practice. Portsmouth, NH.

Schneider, W., Roth, E., \& Ennemoser, M. (2000). Training phonological skills and letter knowledge in children at risk for dyslexia: A comparison of three kindergarten intervention programs. Journal of Educational Psychology, 92, 284-295. http://dx.doi.org/10.1037/0022-0663.92.2.284

Sedaghati, S., Foroughi, R., Shafiei, B., \& Maracy, M. R. (2010). Prevalence of dyslexia in first to fifth grade elementary students, Isfahan, Iran. Audiol, 19(1), 1-8.

Seif-e-naraghy, M., \& Nadery, E. (2005). Specific Learning Disabilities: Stages of Diagnosis and Rehabilitation Methods (3rd ed.). Tehran: Makial.

Shaywitz, B. A., Blachman, B., Pugh, K., Fulbright, R., \& Skudlarski, P. (2004). Development of left occipito-temporal systems for skilled reading in children after a phonologically-based intervention. Biological Psychiatry, 55, 926-933. http://dx.doi.org/10.1016/j.biopsych.2003.12.019

Stenneken, P., Egetemeir, J., Schulte-Körne, G., Müller, H. J., Schneider, W. X., \& Finke, K. (2011). Slow perceptual processing at the core of developmental dyslexia: A parameter-based assessment of visual attention. Neuropsychologia, 49(12), 3454-3465. http://dx.doi.org/10.1016/j.neuropsychologia.2011.08.021

Talcott, J. B., Hansen, P. C., Assoku, E. L., \& Stein, J. F. (2000). Visual motion sensitivity in dyslexia: Evidence for temporal and energy integration deficits. Neuropsychologia, 38(7), 935-943. http://dx.doi.org/10.1016/S0028-3932(00)00020-8

Tallal, P., Miller, S., \& Fitch, R. H. (1995). Neurobiological basis of speech: A case for the preeminence of temporal processing. Irish Journal of Psychology, 16(3), 194-219. http://dx.doi.org/10.1080/03033910.1995.10558057

Taylor, R., \& Sennott, J. (1984). Navigation system and method. Google Patents.

Thomson, M. E. (1984). Developmental dyslexia: Its nature, assessment and remediation. Edward Arnold London.

Thornton, C. A., Jones, G. A., \& Toohey, M. A. (1982). A multisensory approach to thinking strategies for remedial instruction in basic addition facts. Journal for Research in Mathematics Education, 14(3), 198-203. http://dx.doi.org/10.2307/748382

Torgesen, J. K., Wagner, R. K., Rashotte, C. A., Rose, E., Lindamood, P., \& Conway, T. (1999). Preventing reading failure in young children with phonological processing disabilities: Group and individual responses to instruction. Journal of Educational Psychology, 91, 579-593. http://dx.doi.org/10.1037/0022-0663.91.4.579

Uhry, J., \& Clark, D. B. (2005). Dyslexia Theory and Practice of Instruction. Baltimore: York Press, Inc.

Vadasy, P. F., Sanders, E. A., Peyton, J. A., \& Jenkins, J. R. (2002). Timing and intensity of tutoring: A closer look at the conditions for effective early literacy tutoring. Learning Disabilities Research and Practice, 17, 227-241. http://dx.doi.org/10.1111/1540-5826.00048

Vaughn, S., \& Linan-Thompson, S. (2003). What is special about special education for students with learning disabilities? The Journal of Special Education, 37(3), 140-147. http://dx.doi.org/10.1177/00224669030370030301

Vaughn, S., \& Roberts, G. (2007). Secondary interventions in reading: Providing additional instruction for students at risk. Teaching Exceptional Children, 39, 40-46.

Wang, L. C., Tasi, H. J., \& Yang, H. M. (2012). Cognitive inhibition in students with and without dyslexia and dyscalculia. Research in developmental disabilities, 33(5), 1453-1461. http://dx.doi.org/10.1016/j.ridd.2012.03.019

Weiler, M. D., Bernstein, J. H., Bellinger, D., \& Waber, D. P. (2002). Information processing deficits in children 
with attention-deficit/hyperactivity disorder, inattentive type, and children with reading disability. Journal of Learning Disabilities, 35(5), 449-462. http://dx.doi.org/10.1177/00222194020350050501 